Special Issue of the 6th International Congress \& Exhibition (APMAS2016), Maslak, Istanbul, Turkey, June 1-3, 2016

\title{
Synthesis of Nickel-Doped $\mathrm{TiO}_{2}$ Thin Films and Their Structural and Optical Properties at Different Annealing Temperatures
}

\author{
A. Hojabri*, M. Adavi And F. HajakBari \\ Department of Physics, Karaj Branch, Islamic Azad University, Karaj, Iran
}

\begin{abstract}
Titanium oxide $\left(\mathrm{TiO}_{2}\right)$ and nickel-doped $\mathrm{TiO}_{2}$ thin films were deposited onto glass substrates by reactive DC magnetron sputtering technique at different oxygen contents. Then, prepared films were annealed at temperatures of 300 and $500{ }^{\circ} \mathrm{C}$. Influence of $\mathrm{O}_{2} /$ Ar ratio, nickel doping and annealing temperature on structural, morphological and optical properties of $\mathrm{TiO}_{2}$ thin films were studied and discussed. The XRD analysis results have confirmed the amorphous nature of the films. The results show that increase of annealing temperature and oxygen content in argon-oxygen gas mixture have lead to an increase of films transparency. By doping the $\mathrm{TiO}_{2}$ with nickel the optical band gap energy has slightly decreased. AFM analysis results have shown that the surface morphology of films is effectively influenced by annealing temperature.
\end{abstract}

DOI: 10.12693/APhysPolA.131.386

PACS/topics: 81.20.Fw, 81.07.-b, 81.15.cd

\section{Introduction}

Titanium oxide $\left(\mathrm{TiO}_{2}\right)$ thin films, owing to their excellent properties including, chemical stability, low cost, large optical band gap and photocatalytic activity at visible light [1-4], have attracted much attentions in recent years. Metal and nonmetal doping of $\mathrm{TiO}_{2}$ have been used to extend the absorption edge towards the visible light range and to improve the photocatalytic activity [5-8]. Several physical and chemical methods have been reported for growth of $\mathrm{TiO}_{2}$ and doped- $\mathrm{TiO}_{2}$ thin films [1-8]. In this work, nickel doped $\mathrm{TiO}_{2}$ thin films were grown on glass substrates by means of DC reactive magnetron sputtering. Many factors, such as preparation method, deposition parameters, amount and type of dopants and annealing process, can affect the physical properties of $\mathrm{TiO}_{2}$ thin films. Therefore the focus of this work is to investigate the effect of $\mathrm{O}_{2} / \mathrm{Ar}$ ratio and annealing temperature on structural, morphological and optical properties of $\mathrm{TiO}_{2}$ and $\mathrm{Ni}$-doped $\mathrm{TiO}_{2}$ thin films.

\section{Experimental details}

$\mathrm{TiO}_{2}$ and $\mathrm{Ni}$-doped $\mathrm{TiO}_{2}$ thin films were deposited on glass substrate by reactive DC magnetron sputtering of Ti target in gas mixture of $\mathrm{Ar}$ and $\mathrm{O}_{2}$ at a fixed total pressure and varying gas composition $\left(20 \% \mathrm{O}_{2}, 80 \% \mathrm{Ar}\right.$ and $\left.40 \% \mathrm{O}_{2}, 60 \% \mathrm{Ar}\right)$. The titanium target was $75 \mathrm{~mm}$ in diameter, with $3 \mathrm{~mm}$ thickness, $99.999 \%$ purity. Nickel pieces ( $8.5 \mathrm{~mm}$ in diameter, $2 \mathrm{~mm}$ in thickness, $99.99 \%$ ) were fixed on the titanium target, for doping $\mathrm{TiO}_{2}$ films. Thus the concentration of nickel doped into the $\mathrm{TiO}_{2}$ films can

*corresponding author; e-mail: hojabri@kiau.ac.ir be controlled simply by adjusting the area of nickel pieces, fixed on the titanium target. The glass substrates were ultrasonically cleaned with acetone and ethanol before introducing into the deposition chamber. The target to substrate distance was kept at $7 \mathrm{~cm}$. The base pressure was $3.5 \times 10^{-5}$ mbar and the pressure during deposition was about $6.5 \times 10^{-3}$ mbar. Sputtering power of $140 \mathrm{~W}$ was used and all films were deposited during 60 min. Finally, the prepared films were annealed in oxygen atmosphere at temperatures of $300{ }^{\circ} \mathrm{C}$ and $500{ }^{\circ} \mathrm{C}$ for $60 \mathrm{~min}$. Structural properties of the prepared films were analyzed by X-ray diffraction (XRD, Philips, pw 1800) with $\mathrm{Cu} \mathrm{K}_{\alpha}$ radiation. The surface morphology of the deposited films was examined by atomic force microscopy (AFM, Park Scientific Instrument, Auto probe cp USA) and the optical transmittance spectra of the films were measured using a spectrophotometer (CARY 500 Scan) in the range of $200-1100 \mathrm{~nm}$.

\section{Results and discussion}

The XRD patterns of the pure and Ni-doped $\mathrm{TiO}_{2}$ thin films prepared at different $\mathrm{O}_{2}$ contents after annealing at $300{ }^{\circ} \mathrm{C}$ are shown in Fig. 1. We can observe a broad peak at $2 \theta=24^{\circ}$ in all XRD patterns, which is due to glass substrate. The absences of any clear peaks in XRD patterns suggests that the films are amorphous. The films prepared at annealing temperature of $500^{\circ} \mathrm{C}$ also exhibit an amorphous-like nature. The XRD patterns of these films are not shown here.

The optical transmittance spectra of the annealed films at temperatures of $300{ }^{\circ} \mathrm{C}$ and $500{ }^{\circ} \mathrm{C}$ in the wavelength range $200-1100 \mathrm{~nm}$ are shown in Fig. $2 \mathrm{~A}$ and $\mathrm{B}$, respectively. The spectra reveal that $\mathrm{TiO}_{2}$ thin films are transparent in the visible region and transparency exhibits a sharp decrease in the ultra violet region. All Ni-doped $\mathrm{TiO}_{2}$ films are also transparent and colorless, similar to 


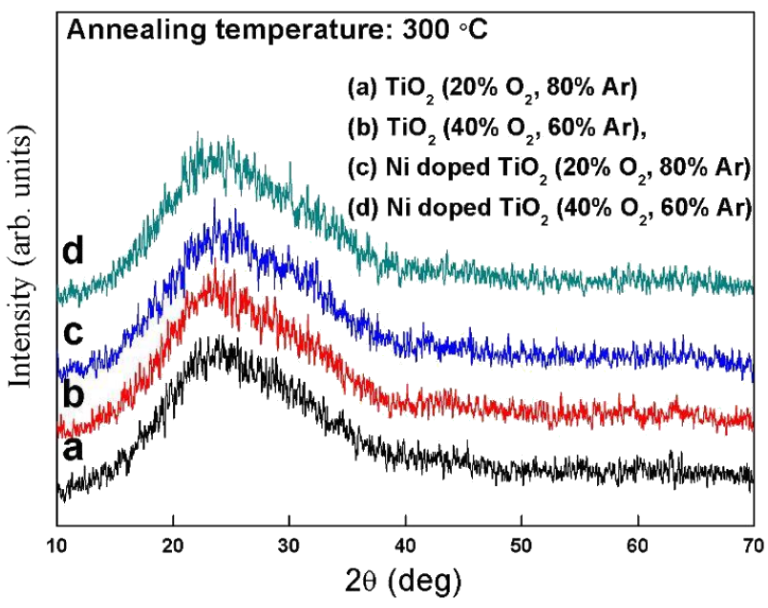

Fig. 1. The XRD patterns of the $\mathrm{TiO}_{2}$ and Ni-doped $\mathrm{TiO}_{2}$ films after annealing at $300{ }^{\circ} \mathrm{C}$.

pure $\mathrm{TiO}_{2}$ films. Doping of $\mathrm{TiO}_{2}$ with Ni leads to decrease of average transmittance due to the structure distortion of $\mathrm{TiO}_{2}$ thin films. Also the transmittance increases gradually by increase of $\mathrm{O}_{2}$ content in $\left(\mathrm{Ar}+\mathrm{O}_{2}\right)$ gas and of annealing temperature. Furthermore, the absorption edge of Ni-doped $\mathrm{TiO}_{2}$ thin films is slightly shifted towards visible range [4-8].
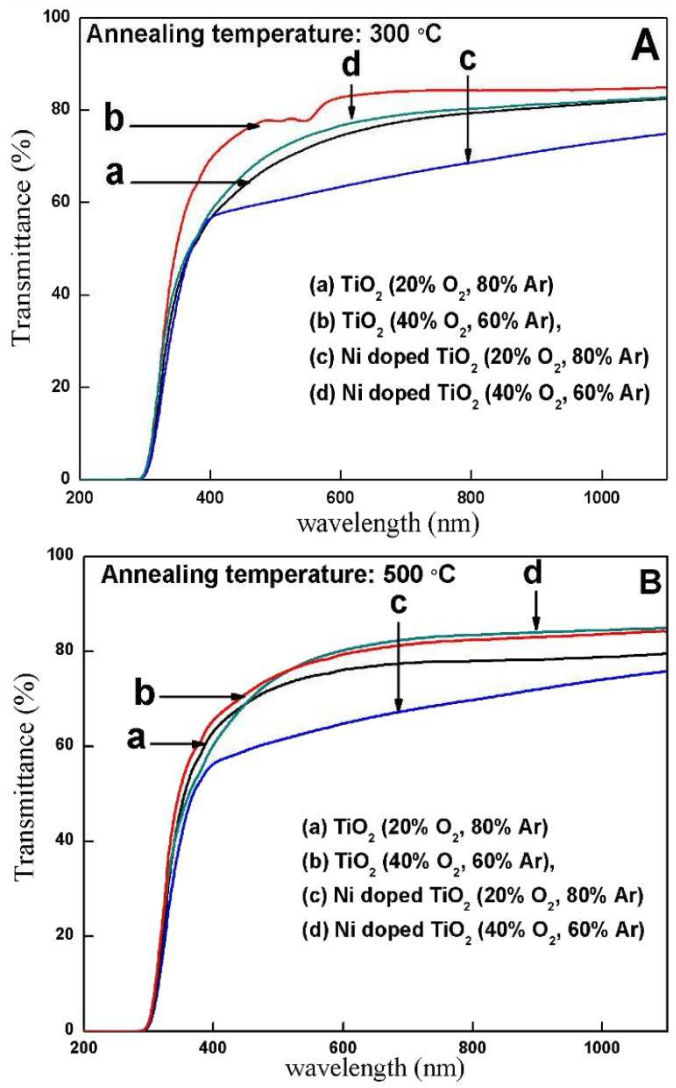

Fig. 2. Transmittance spectra of the $\mathrm{TiO}_{2}$ and Nidoped $\mathrm{TiO}_{2}$ films after annealing at (A) $300{ }^{\circ} \mathrm{C}$ and (B) $500^{\circ} \mathrm{C}$.
The absorption coefficient $\alpha$ was calculated from the optical transmittance $T$ using the Lambert formula, $\alpha=1 / t \ln (1 / T)[9]$ where, $t$ is the thickness of films. The direct optical band gap $E_{\mathrm{g}}$ of the films annealed at temperature of $300^{\circ} \mathrm{C}$ was calculated from the plot of $(\alpha h \nu)^{2}$ versus photon energy $h \nu$, by extrapolating the linear portion to zero absorption coefficient $(\alpha=0)[9,10]$. Figure 3 shows the plot of $(\alpha h \nu)^{2}$ versus photon energy $\mathrm{h} \nu$ of the pure $\mathrm{TiO}_{2}$ and $\mathrm{Ni}$-doped $\mathrm{TiO}_{2}$ films after annealing at temperature of $300^{\circ} \mathrm{C}$. The optical band gap value of non-doped $\mathrm{TiO}_{2}$ thin films prepared at $(20 \%$ $\left.\mathrm{O}_{2}, 80 \% \mathrm{Ar}\right)$ and $\left(40 \% \mathrm{O}_{2}, 60 \% \mathrm{Ar}\right)$ was $4.08 \mathrm{eV}$ and $4.1 \mathrm{eV}$ (Fig. 3a and b), respectively. After doping of $\mathrm{TiO}_{2}$ thin films with $\mathrm{Ni}$, the band gap values have changes to 4.04 for $\mathrm{Ni}$ doped $\mathrm{TiO}_{2}\left(20 \% \mathrm{O}_{2}, 80 \%\right.$ Ar) (Fig. 3c) and $4.07 \mathrm{eV}$ for $\mathrm{Ni}$ doped $\mathrm{TiO}_{2}\left(40 \% \mathrm{O}_{2}, 60 \%\right.$ Ar) (Fig. 3d). The optical band gap values, estimated by Tauc plots, are greater than the values of bulk band gap of $\mathrm{TiO}_{2}$, which indicates the formation of nanoparticles [3]. Optical band gap also slightly decreased with doping of $\mathrm{TiO}_{2}$ thin films with nickel.

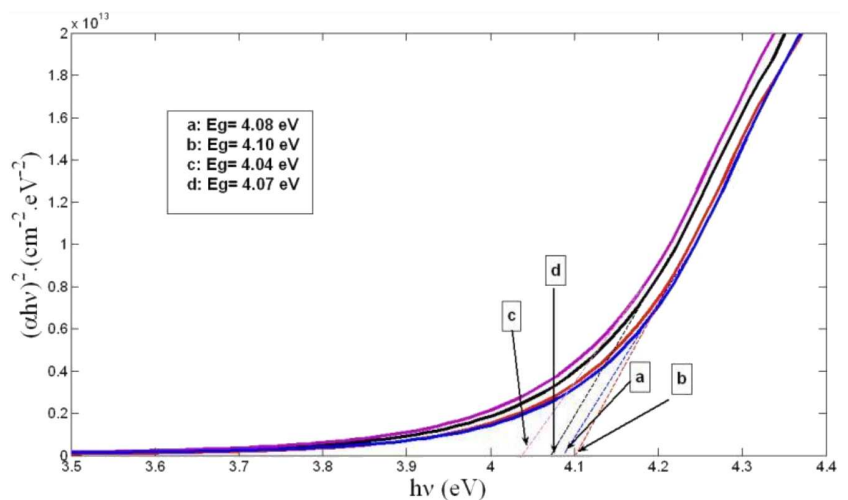

Fig. 3. The plot of $(\alpha h \nu)^{2}$ versus photon energy $h \nu$ of the $\mathrm{TiO}_{2}$ and Ni-doped $\mathrm{TiO}_{2}$ films after annealing at $300{ }^{\circ} \mathrm{C}$ (a) $\mathrm{TiO}_{2}\left(20 \% \mathrm{O}_{2}, 80 \%\right.$ Ar), (b) $\mathrm{TiO}_{2}\left(40 \% \mathrm{O}_{2}\right.$, $60 \% \mathrm{Ar})$, (c) Ni-doped $\mathrm{TiO}_{2}\left(20 \% \mathrm{O}_{2}, 80 \% \mathrm{Ar}\right)$ and (d) Ni-doped $\mathrm{TiO}_{2}\left(40 \% \mathrm{O}_{2}, 60 \% \mathrm{Ar}\right)$.

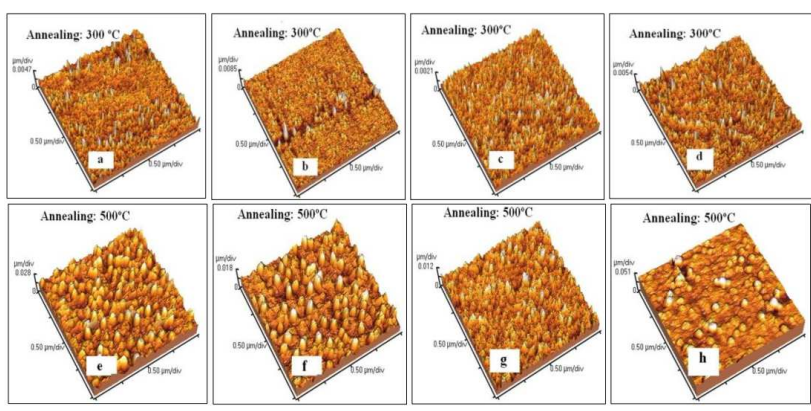

Fig. 4. 3D AFM images of the $\mathrm{TiO}_{2}$ and $\mathrm{Ni}$-doped $\mathrm{TiO}_{2}$ films after annealing at $300{ }^{\circ} \mathrm{C}$ and $500^{\circ} \mathrm{C}$. (a, e) $\mathrm{TiO}_{2}\left(20 \% \mathrm{O}_{2}, 80 \% \mathrm{Ar}\right)$, (b, f) $\mathrm{TiO}_{2}\left(40 \% \mathrm{O}_{2}, 60 \%\right.$ $\mathrm{Ar}),(\mathrm{c}, \mathrm{g}) \mathrm{Ni}$-doped $\mathrm{TiO}_{2}\left(20 \% \mathrm{O}_{2}, 80 \% \mathrm{Ar}\right)$ and $(\mathrm{d}, \mathrm{h})$ Ni-doped $\mathrm{TiO}_{2}\left(40 \% \mathrm{O}_{2}, 60 \% \mathrm{Ar}\right)$.

Surface morphology of thin films is one of the most important factors that can influence the application of films. 
Therefore, surface morphology and the roughness of the prepared films were examined by AFM analysis. The three-dimensional AFM images of the deposited films are shown in Fig. 4. The scan area for all images was $2 \times 2 \mu \mathrm{m}^{2}$. The surface roughness of films is very small. For the films annealed at $300{ }^{\circ} \mathrm{C}$ the root means square (RMS) roughness was in range of $0.46-1.12 \mathrm{~nm}$ and by increasing the annealing temperature to $500^{\circ} \mathrm{C}$ the RMS roughness was increased and has reached the range of 2.52-7.24 nm. We can observe that the surface morphology of films was highly influenced by $\mathrm{O}_{2} / \mathrm{Ar}$ ratio, dopants and annealing temperatures [3, 7, 11-14].

\section{Conclusions}

Transparent $\mathrm{TiO}_{2}$ and Ni-doped $\mathrm{TiO}_{2}$ films were grown on glass substrates by reactive DC magnetron sputtering method. The XRD results have shown that the prepared films were amorphous. The films surface morphology is effectively influenced by $\mathrm{O}_{2} / \mathrm{Ar}$ ratio, dopants and annealing temperatures. All Ni-doped $\mathrm{TiO}_{2}$ films are transparent and colorless, similar to pure $\mathrm{TiO}_{2}$ films. Doping of $\mathrm{TiO}_{2}$ with $\mathrm{Ni}$ has led to a decrease of average transmittance. The optical band gap values, estimated by Tauc plots, are greater than the values of bulk band gap of $\mathrm{TiO}_{2}$, which indicates the formation of nanoparticles. It was found that the optical band gap slightly decreased at doping of the $\mathrm{TiO}_{2}$ with nickel.

\section{Acknowledgments}

This work was supported by Islamic Azad University, Karaj Branch, Karaj, Iran.

\section{References}

[1] L.A. Patil, D.N. Suryawashi, I.G. Pathan, D.M. Patial, Sens. Actuators B: Chem. 176, 514 (2013).

[2] B. Duymaz, Z.V. Yigit, M.G. Seker, F. Dundar, Acta Phys. Pol. A 129, 872 (2016).

[3] K. Eufinger, D. Poelman, H. Poelman, R. De Gryse, G.B. Marin, Thin Solid Films: Process Appl., 2008, p. 189.

[4] P. Manurung, Y. Putri, W. Simanjuntak, I.M. Low, Ceram. Int. 39, 255 (2013).

[5] J.O. Carneiro, V. Teixeira, A. Portinha, A. Magalhaes, P. Coutinho, C.J. Tavares, R. Newton, Matter. Sci. Eng. B 138, 144 (2007).

[6] D. Fischer, Thin Solid Films 598, 204 (2016).

[7] I. Karabay, S. Aydin Yuksel, F. Ongul, S. Ozturk, M. Asli, Acta Phys Pol. A 121, 265 (2012).

[8] G. Wan, S. Wang, X. Zhang, M. Huang, Y. Zhang, W. Duan, L. Yi, Appl. Surf. Sci. 357, 622 (2015).

[9] F. Hajakbari, F. Shafieinejad, Jpn. J. Appl. Phys. 55, 035503 (2016).

[10] A. Hojabri, J. Theor. Appl. Phys. 10, 219 (2016).

[11] A. Hojabri, F. Hajakbari, A. Emami Meibody, M.A. Moghri Moazzen, Acta Phys. Pol. A 123, 307 (2013).

[12] A. Hojabri, S. Pourmohammad, Acta Phys. Pol. A 129, 647 (2016).

[13] F. Hajakbari, M. Ensandoust, Acta Phys. Pol. A 129, 680 (2016).

[14] Y. Wan, B. Sun, Z. Xu, W. Chao, Appl. Surf. Sci. 258, 4347 (2012). 